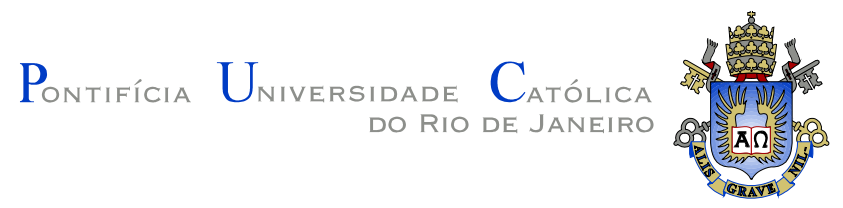

Luiz Felipe de Souza e Silva

\title{
Inspeção Não-Intrusiva da Comunicação em Aplicações Baseadas em RPC
}

\author{
Dissertação de Mestrado
}

Dissertação apresentada como requisito parcial para obtenção do grau de Mestre pelo Programa de Pós-graduação em Informática do Departamento de Informática da PUC-Rio

Orientador: Prof. Renato Fontoura de Gusmão Cerqueira 
Luiz Felipe de Souza e Silva

\section{Inspeção Não-Intrusiva da Comunicação em Aplicações Baseadas em RPC}

Dissertação apresentada como requisito parcial para obtenção do grau de Mestre pelo Programa de Pós-graduação em Informática do Departamento de Informática da PUC-Rio. Aprovada pela Comissão Examinadora abaixo assinada.

Prof. Renato Fontoura de Gusmão Cerqueira
Orientador
Departamento de Informática - PUC-Rio

Prof. Marcus Endler

Departamento de Informática - PUC-Rio

Prof. Alexandre Sztajnberg

Universidade do Estado do Rio de Janeiro

Prof. José Eugênio Leal

Coordenador Setorial do Centro Técnico Científico - PUC-Rio

Rio de Janeiro, 8 de abril de 2013 
Todos os direitos reservados. É proibida a reprodução total ou parcial do trabalho sem autorização da universidade, do autor e do orientador.

\section{Luiz Felipe de Souza e Silva}

Graduou-se em Engenharia Elétrica com ênfase em Eletrônica e Computação na UFRJ - Universidade Federal do Rio de Janeiro - em 2007. Trabalhou na Globo.com como engenheiro de webmedia até Junho de 2008. Certificado RHCE em 2010, atualmente trabalha como analista de sistemas com ênfase em infraestrutura na gerência de Tecnologia Geofísica da Petrobras S/A.

Ficha Catalográfica

Souza e Silva, Luiz Felipe de

Inspeção Não-Intrusiva da Comunicação em Aplicações Baseadas em RPC / Luiz Felipe de Souza e Silva ; orientador: Renato Fontoura de Gusmão Cerqueira. - Rio de Janeiro : PUC-Rio, Departamento de Informática, 2013.

[], 85 f. : il. (color.) ; $30 \mathrm{~cm}$

Dissertação (mestrado) - Pontifícia Universidade Católica do Rio de Janeiro, Departamento de Informática, 2013.

Inclui bibliografia

1. Informática - Teses. 2. Depuração de aplicações distribuídas.

3. Chamadas de sistemas. 4. Monitoramento não intrusivo. 5. Interceptação de chamadas. I. Cerqueira, Renato Fontoura de Gusmão. II. Pontifícia Universidade Católica do Rio de Janeiro. Departamento de Informática. III. Título. 


\section{Agradecimentos}

Grandes projetos nunca são concluídos pela mão de um único indivíduo. Mesmo quando, devido a uma determinada conquista, apenas uma pessoa fica em evidência, esta não a conquistou sem recorrer à ajuda de terceiros, sejam elas entidades religiosas, orientadores acadêmicos, pais, família, amigos ou colegas de trabalho. Convergente a este raciocínio, este projeto não foi diferente. Devo muito a Deus, a minha família, e as demais pessoas que me ajudaram ao longo deste longo caminho por todo apoio nos momentos difíceis e a compreensão pelas ausências ao longo desses últimos anos, o que creio que seja comum a todos os mestrandos.

Em especial, agradeço, na Petrobras, ao Luis Antônio, meu coordenador, e ao Edson Yoshino, meu gerente imediato, por terem buscado, na empresa, o patrocínio necessário para que eu pudesse concluir o mestrado, mesmo quando não havia condição favorável para tal. Na PUC-Rio, não posso deixar de agradecer ao meu orientador acadêmico, professor Renato Cerqueira, por todo apoio, empenho e dedicação para que houvesse sucesso no meu ingresso no programa de pós-graduação desta entidade, e também por todo período que frequentei o programa, sem esquecer da professora Noemi Rodriguez, por sua enorme paciência em me escutar e aconselhar nos momentos mais tensos.

Aos amigos, Roberto Gonzalez, por ter dado a semente que culminou neste trabalho, e ao Amadeu Barbosa, pelo seu apoio incondicional nos instantes finais e decisivos para conclusão deste trabalho. 


\section{Resumo}

Souza e Silva, Luiz Felipe de; Cerqueira, Renato Fontoura de Gusmão (Orientador). Inspeção Não-Intrusiva da Comunicação em Aplicações Baseadas em RPC. Rio de Janeiro, 2013. 85p. Dissertação de Mestrado - Departamento de Informática, Pontifícia Universidade Católica do Rio de Janeiro.

A depuração de software é uma atividade que tipicamente demanda um grande esforço, fundamentalmente devido à necessidade de analisar múltiplas condições que determinam o contexto de execução do software e de criar suposições que expliquem o motivo do defeito, para, só assim, sermos capazes de corrigi-lo. No caso de sistemas distribuídos, o paralelismo, a ordem de escalonamento, os atrasos na comunicação e falhas nos equipamentos são exemplos de fatores que aumentam ainda mais a complexidade da atividade de depuração. Portanto, a busca por ferramentas que auxiliem neste processo é contínua. Neste trabalho, propomos uma ferramenta de monitoração e visualização, não intrusiva, da comunicação entre componentes de sistemas distribuídos, através do uso de analisadores de protocolo de comunicação e da monitoração das chamadas de sistema de leitura e gravação.

\section{Palavras-chave}

Depuração de aplicações distribuídas; chamadas de sistema; monitoramento não intrusivo; interceptação de chamadas. 


\section{Abstract}

Souza e Silva, Luiz Felipe de; Cerqueira, Renato Fontoura de Gusmão (Advisor). Non-Intrusive Communication Inspection in RPC-Based Applications. Rio de Janeiro, 2013. 85p. MSc. Dissertation Departamento de Informática, Pontifícia Universidade Católica do Rio de Janeiro.

Software debugging is an activity that typically requires an huge effort, primarily due to the need to analyze multiple conditions that determine the execution context of the software and to create assumptions that explain the problem, for only thus being able to fix it. In the case of distributed systems, parallelism, order scheduling, delays in communication and equipment failures are examples of factors that further increase the complexity of the debugging activity. Therefore, the search for tools that assist in this process is continuous. In this dissertation, we propose a tool for non-intrusive monitoring and visualization of communications between components of distributed systems, based on communication protocol analyzers and monitoring of read and write system calls.

\section{Keywords}

Debugging of Distributed Systems; System Calls; Non-intrusive Monitoring; Call Interception. 


\section{Sumário}

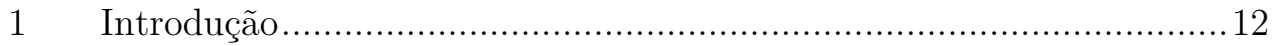

1.1 Ciclo de depuração de um software .............................................. 13

1.2 Depuração aplicada a sistemas distribuídos .................................... 13

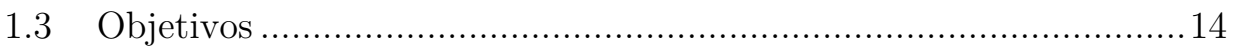

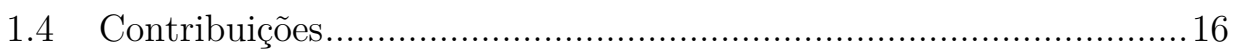

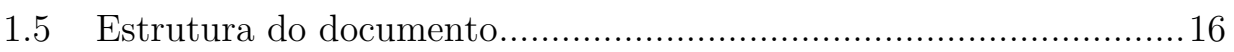

2 Metodologias, técnicas e soluções de depuração ……........................... 17

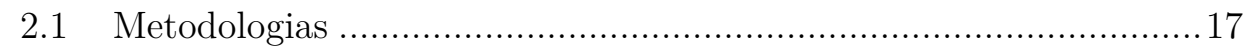

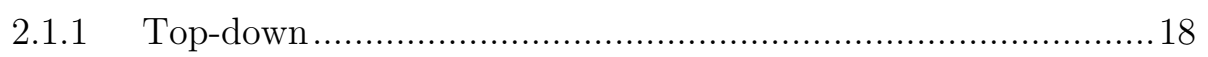

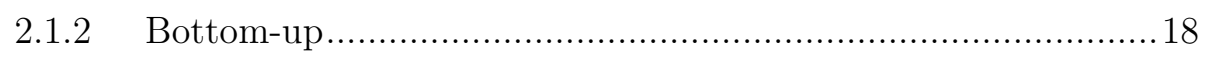

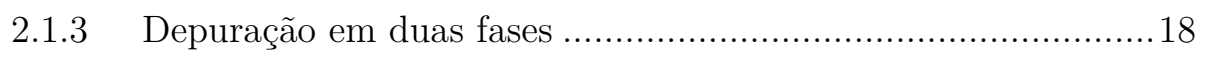

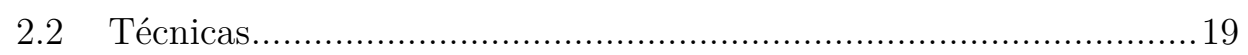

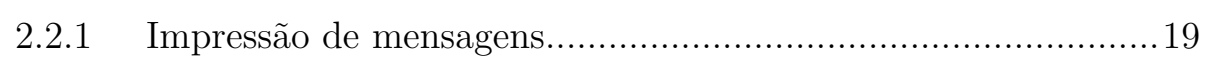

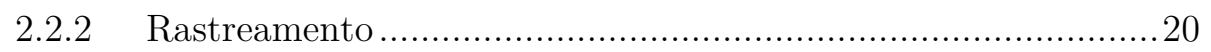

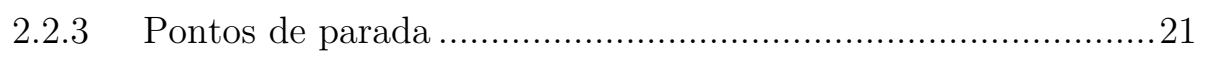

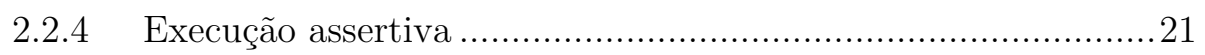

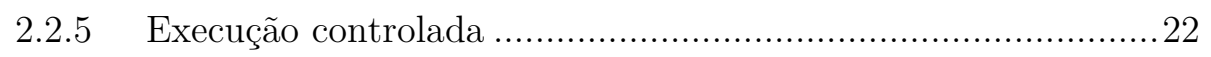

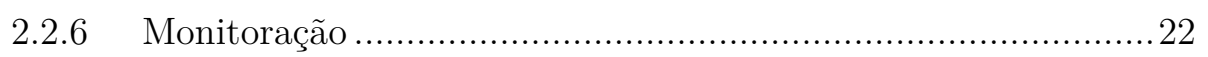

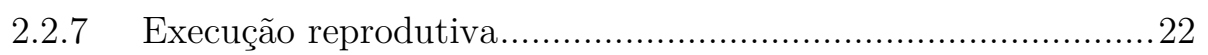

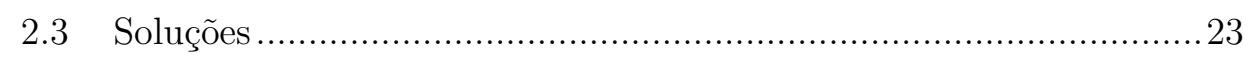

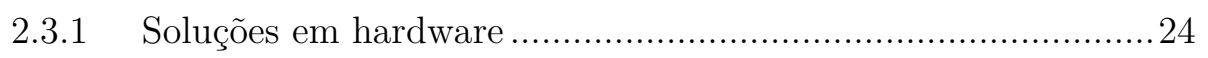

2.3.2 Soluções no núcleo do sistema operacional................................24

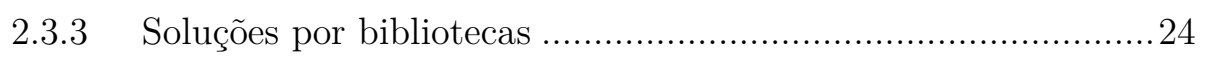

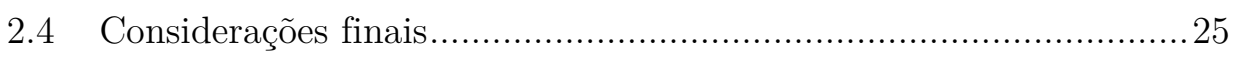

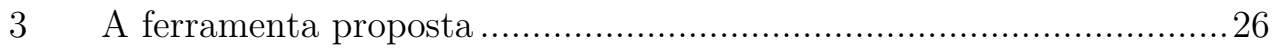

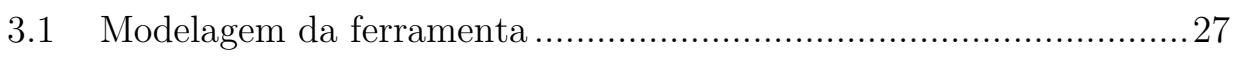

3.2 Instrumentação do núcleo do SO..............................................29

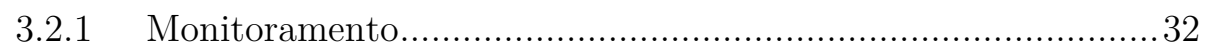

3.2.2 Dispositivo de comunicação com o modo usuário........................35

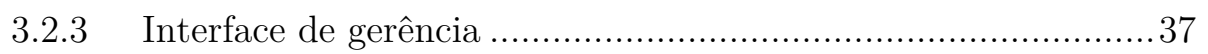

3.3 Formato das mensagens de instrumentação ...................................38

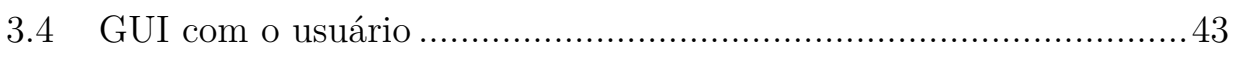

3.5 Metodologias de utilização....................................................... 47

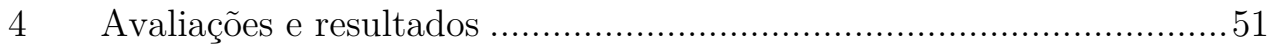

4.1 Desempenho do código inserido no núcleo.....................................51

4.1.1 Degradação no ponto de entrada ........................................5 54

4.1.2 Degradação ao gravar no buffer circular ............................... 61

4.2 Avaliação do desempenho da interface núcleo-usuário .....................68

4.3 Avaliação do desempenho da interface GUI ..................................69

4.4 Avaliação funcional ..................................................................... 70 
4.4.1 Preparação do ambiente para testes ..........................................71

4.4.2 Conexão a um servidor de mensagens ...................................... 72

4.4.3 Troca de mensagens CORBA utilizando DII/DSI.....................73

4.4.4 Gerenciador de pregão eletrônico ...............................................74

4.4.5 Gerenciador de pregão eletrônico com notificações ...................76

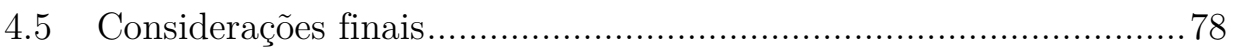

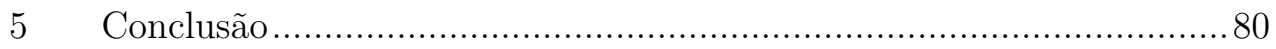

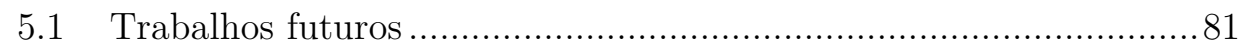

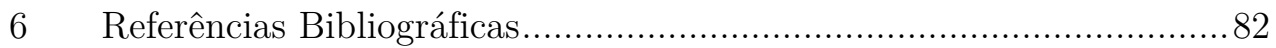




\section{Lista de Figuras}

Figura 2.1 Rastreamento da biblioteca C padrão ................................................ 20

Figura 2.2 Rastreamento de chamadas a bibliotecas .......................................... 20

Figura 2.3 Rastreamento de chamadas de sistema ............................................ 21

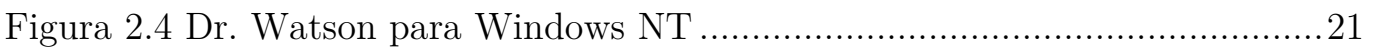

Figura 2.5 Falha de assertividade do runtime do Visual C ..................................22

Figura 3.1 Representação gráfica da ferramenta .............................................2 26

Figura 3.2 Indireções formadas pelo vetor de chamadas de sistema .....................22

Figura 3.3 Executando uma chamada de sistema..............................................2

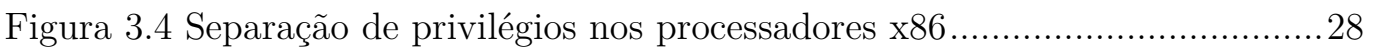

Figura 3.5 Entrada/saída da monitoração de leitura............................................. 30

Figura 3.6 O módulo, antes e depois ........................................................... 31

Figura 3.7 Isolamento do monitoramento e interface núcleo-usuário .....................332

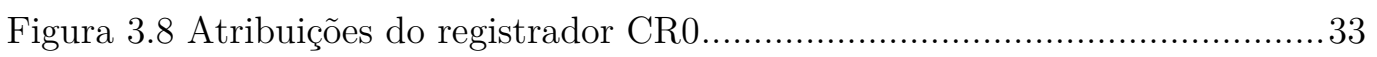

Figura 3.9 Pseudocódigo do método da força bruta ............................................... 33

Figura 3.10 Os dois vetores de chamadas de sistema ........................................... 34

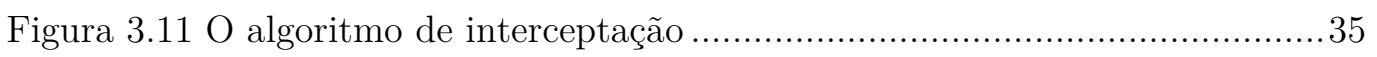

Figura 3.12 Mensagem de saída apresentada após a carga do módulo ...................36

Figura 3.13 Status do funcionamento do módulo ............................................... 37

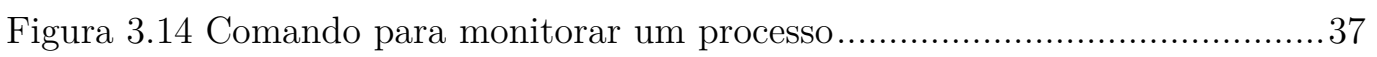

Figura 3.15 Comando para remover monitoração de um processo ……..................38

Figura 3.16 Incluindo processos parentes na monitoração .................................... 38

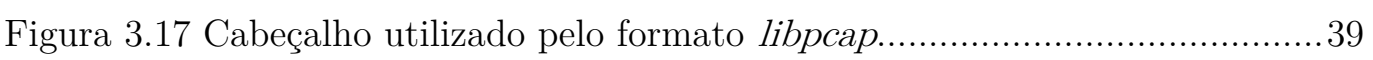

Figura 3.18 O processo de encapsulamento de um pacote TCP/IP ......................4 40

Figura 3.19 Binary Encoding Representation................................................... 42

Figura 3.20 A interface do wireshark ............................................................ 43

Figura 3.21 Campo opcional IP com as informações de processo ......................... 44

Figura 3.22 Campo opcional IP manipulado pela extensão ................................. 44

Figura 3.23 Acesso ao filtro rápido do Wireshark ............................................. 45

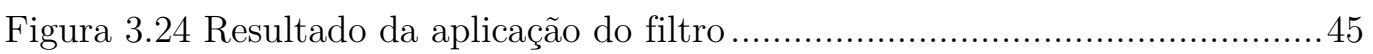

Figura 3.25 Interpretação nativa do protocolo GIOP ...........................................46

Figura 3.26 Uso da IDL para obter mais informações do pacote...........................46

Figura 3.27 Acesso ao filtro rápido no Wireshark ................................................... 47

Figura 3.28 Elos de comunicação entre componentes A e B.................................. 48

Figura 3.29 Topologias de comunicação ........................................................ 49

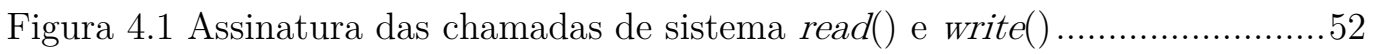

Figura 4.2 Cálculo da quantidade de eventos necessários para ler um arquivo .....52

Figura 4.3 Diagrama do algoritmo aplicado na função de entrada ........................53

Figura 4.4 Diagrama do algoritmo de identificação do socket ..............................54

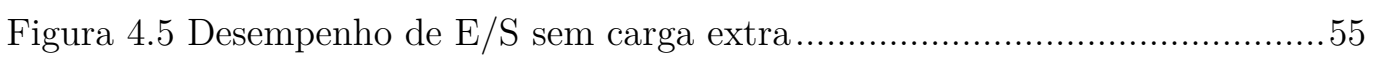

Figura 4.6 Desempenho de E/S com a monitoração habilitada ..............................56

Figura 4.7 Desempenho de E/S do processo monitorado......................................57

Figura 4.8 Utilização de CPU com os testes da seção 4.1.1.2 ..............................59

Figura 4.9 Processos concorrentes observados nos testes da seção 4.1.1.2 .............59 
Figura 4.10 Utilização de CPU com os testes da seção 4.1.1.3 ….........................60

Figura 4.11 Concorrência dos processos nos testes da seção 4.1.1.3 .....................61

Figura 4.12 Desempenho de E/S de rede sem carga extra..................................63

Figura 4.13 Desempenho de E/S de rede com a monitoração habilitada ..............64

Figura 4.14 Desempenho de E/S de rede do processo monitorado ........................65

Figura 4.15 Utilização de CPU com o teste da seção 4.1.2.2 ..................................66

Figura 4.16 Utilização de CPU com o teste da seção 4.1.2.3 ….............................66

Figura 4.17 Concorrência dos processos do teste da seção 4.1.2.2 ….....................67

Figura 4.18 Concorrência dos processos do teste da seção 4.1.2.3 …....................67

Figura 4.19 Desempenho da transformação núcleo $\rightarrow$ usuário ..............................69

Figura 4.20 Desempenho de carga de registros do Wireshark ............................. 70

Figura 4.21 Carregamento do módulo de interceptação de chamadas de sistema .71

Figura 4.22 Criação do vínculo de comunicação núcleo-usuário .............................71

Figura 4.23 Instanciação da camada núcleo-usuário.......................................... 71

Figura 4.24 Instanciação da interface GUI .................................................... 72

Figura 4.25 Captura utilizando o Wireshark ….................................................... 72

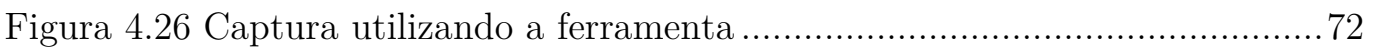

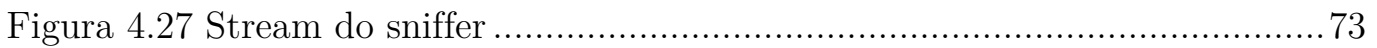

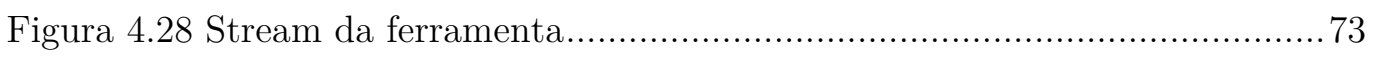

Figura 4.29 Folha obtida com a carga da IDL forjada ........................................ 73

Figura 4.30 Pesquisa utilizando características do pacote GIOP ..........................74

Figura 4.31 Diagrama do software de gerenciamento de pregões .......................... 74

Figura 4.32 Resultado da monitoração do Auction Server .................................... 75

Figura 4.33 Conteúdo da exceção de sistema encapsulada no pacote GIOP .........75

Figura 4.34 Interface do software de pregão eletrônico com notificações ...............76

Figura 4.35 Monitoração do software de pregão eletrônico com notificações.........77

Figura 4.36 Aplicação de filtros para remoção das entradas TCP .........................78 


\section{Lista de Tabelas}

Tabela 3.1 Estrutura utilizada para a comunicação núcleo-usuário ........................37

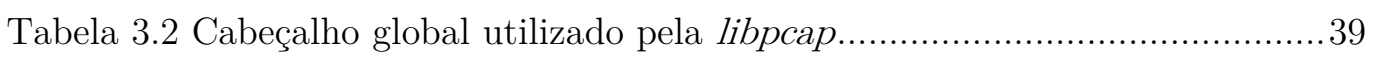

Tabela 3.3 Cabeçalho de cada pacote armazenado no arquivo libpcap ..................39

Tabela 3.4 Estrutura de um pacote TCP/IP ...................................................... 41

Tabela 3.5 Estrutura de um cabeçalho IP opcional..............................................4 41

Tabela 3.6 Campo opcional IP com dados de processo e descritor ....................... 42

Tabela 3.7 Mensagens monitoradas pelo componente A........................................ 48

Tabela 3.8 Mensagens monitoradas pelo componente B....................................... 48

Tabela 4.1 Médias de desempenho obtidas sem carga extra................................56

Tabela 4.2 Médias de desempenho com a monitoração habilitada ........................57

Tabela 4.3 Médias de desempenho do processo monitorado ................................58

Tabela 4.4 Incremento de tempo de E/S percentual da seção 4.1.1.2 / 4.1.1.1 .....58

Tabela 4.5 Incremento de tempo de E/S percentual da seção 4.1.1.3 / 4.1.1.1 ....60

Tabela 4.6 Diferença percentual relativa entre as tabelas 4.5 e $4.4 \ldots \ldots \ldots \ldots \ldots \ldots \ldots . . . .60$

Tabela 4.7 Médias de desempenho de rede obtidas sem carga extra .....................62 62

Tabela 4.8 Médias de desempenho de rede obtidas com a monitoração habilitada63

Tabela 4.9 Médias de desempenho do processo monitorado ................................64

Tabela 4.10 Incremento de tempo de E/S percentual da seção 4.1.2.2 / 4.1.2.1 ...65

Tabela 4.11 Incremento de tempo de E/S percentual da seção 4.1.2.3 / 4.1.2.1 ...65

Tabela 4.12 Diferença percentual relativa entre as tabelas 4.9 e 4.8 ....................68

Tabela 4.13 Médias de desempenho da interface ..................................................68

Tabela 4.14 Médias de desempenho do Wireshark ................................................69 